\title{
O BRASIL MODERNO E A EDUCAÇÃO PARA O TRABALHO EM CUIABÁ: A ESCOLA DE APRENDIZES ARTÍFICES DE MATO GROSSO (1909-1942)
}

\author{
Túlio Marcel Rufino de Vasconcelos Figueiredo ${ }^{1}$ \\ Edna Mendonça Oliveira de Queiroz ${ }^{2}$
}

\section{Resumo}

Este texto apresenta os resultados de uma pesquisa de mestrado que investigou as relações entre a modernizaçáo brasileira e a implantação de uma escola que formava jovens para o trabalho em Cuiabá, MT, no período de 1909 a 1942. Essa escola, denominada na época de Escola de Aprendizes Artífices de Mato Grosso (EAAMT), fazia parte de uma rede de instituiçóes federais que tinha, entre seus objetivos, dar aos filhos da classe trabalhadora condiçóes de se ajustarem ao modelo de desenvolvimento econômico que se instalava no Brasil, isto é, o capitalismo dependente. Tomou-se a obra de Florestan Fernandes (1976) como marco referencial, a fim de compreender os nexos do Brasil Moderno com a formação profissional proposta naquele momento. A pesquisa definiu-se como qualitativa, de natureza histórica e documental. Neste estudo, concluiu-se que a proposta educativa da EAAMT se coadunava com os objetivos de formação de trabalhadores afeitos às modernas relações sociais, subordinados às instâncias de poder para fins de controle da ordem social. Embora instalada fora da regiáo Sudeste, expoente do desenvolvimento nacional, não se destoava das suas congêneres, formando jovens mato-grossenses para o exercício de atividades necessárias à vida social moderna, constituindo nexos com os ideais da modernização brasileira.

Palavras-chave: Educação para o trabalho. Modernização brasileira. Escola de Aprendizes Artífices de Mato Grosso.

1 Mestre em Educação, professor do Instituto Federal de Educação, Ciência e Tecnologia de Mato Grosso. E-mail: tulio.figueiredo@ifmt.edu.br

2 Doutora em Educação, professora do Programa de Pós-Graduação em Educação da Faculdade de Educação da Universidade Federal de Goiás. E-mail: ednamqueiroz@gmail.com 


\section{Introdução}

Estudiosos e pesquisadores da história brasileira foram unânimes em registrar a diversidade de ideais que agitavam o contexto econômico, político e social nas primeiras décadas do século XX (FERNANDES, 1976; FAUSTO, 2015; PRADO JÚNIOR, 2011; HOLANDA, 1978). Entre eles, Ianni (1996) analisa que no período havia uma tentativa de adequar o país, que há pouco deixava a condiçấo escravagista e monárquica, aos moldes das naçóes desenvolvidas, com base no trabalho livre e no regime republicano recém-instaurado.

O projeto de sociedade inspirado nos ideais de progresso e modernidade que se implementava nesse movimento, interpretado como "Brasil Moderno", centrava-se nos processos de urbanização e industrializaçáo que constituiriam novas relaçóes sociais, orientadas por princípios e valores exigidos pelo mundo burguês.

Ianni (1996) discute que esse ideal visava ao atendimento dos interesses da classe dominante, que, mais tarde, combinada aos contornos do país, constituiria a burguesia brasileira. Entre as açōes que emergiram naquele momento, destacou-se o projeto de educaçáo voltado aos jovens filhos da classe trabalhadora, com o objetivo de dar condiçôes para que se ajustassem ao novo modelo econômico que se instalava - o capitalismo dependente.

Nesse contexto, foi criada em 1909 uma escola de artes e ofícios em Cuiabá denominada Escola de Aprendizes Artífices de Mato Grosso - EAAMT (BRASIL, 1909). Essa instituição manteve-se até 1942, quando foi transformada na Escola Industrial de Cuiabá. Com o passar dos anos, outras propostas de remodelação da escola foram adotadas, até que, em 2009, se configurou o Instituto Federal de Mato Grosso (IFMT), compreendendo o IFMT/Campus Octayde Jorge da Silva, considerado sucessor da EAAMT.

O vínculo profissional de um dos autores deste texto com o IFMT e os laços históricos entre essas instituiçôes foram as motivaçóes para a realizaçáo da pesquisa de mestrado que deu origem a este texto, defendido no Programa de Pós-Graduação em Educação da Universidade Federal de Goiás (PPGE/ UFG), na linha de Fundamentos dos Processos Educativos.

A pesquisa orientou-se no sentido de responder a quais eram as relaçóes entre o processo de modernização e a educação para o trabalho destinada aos jovens, filhos da classe trabalhadora, nas primeiras décadas do século XX, em Cuiabá, MT. 
Tomou-se, como marco teórico, a interpretação de Florestan Fernandes (1976) sobre a modernização brasileira em sua obra A Revolução Burguesa no Brasil: um ensaio de interpretaçâo sociológica, na qual são analisadas as mediaçôes sociais e históricas que combinavam os ideais capitalistas hegemônicos ao caráter conservador da sociedade brasileira.

A conjuntura histórica que implica a Revolução Burguesa, de que trata Fernandes, dirigiu as relaçóes sociais e econômicas que se materializaram, entre tantas, na rede federal de Escolas de Aprendizes Artífices - EAAs. Esse projeto de educação profissional é compreendido, neste estudo, como um dos nexos do plano maior de modernidade e de civilizaçáo proposto pelo Estado e elite nacional.

A pesquisa configurou-se como qualitativa, de natureza histórica e documental, que contou com o exame de fontes oficiais, documentos produzidos pelas autoridades republicanas do período, fontes da instituição investigada e da literatura referente à história da educação profissional brasileira.

Entre essas fontes, destacaram-se os relatórios expedidos, no período em estudo, pelos Ministérios da Agricultura, Indústria e Comércio (MAIC) e da Saúde e Educação Pública (MESP). Na época, cabiam a essas instâncias superiores a supervisão e a emissão de diretrizes para as escolas de artes e ofícios. Incluíram-se, também, fichas, formulários e boletins expedidos pela EAAMT. Por meio desses documentos foi possível conhecer a história das EAAs, em especial da EAAMT, e desvelar os nexos e as contradiçóes constitutivas dos processos modernizadores enredados à formação profissional em estudo.

$\mathrm{O}$ texto está dividido em três partes. Inicia-se procurando indicar, em linhas básicas, os fundamentos históricos dos processos econômicos, políticos e sociais defendidos pelo Estado republicano e pela elite nacional, os quais buscavam modernizar o Brasil das últimas décadas do século XIX ao início do XX. Em seguida, apresenta-se o projeto da rede nacional de escolas de artes e ofícios como um amplo projeto republicano de modernidade.

No terceiro momento, aborda-se a EAAMT, sua criação e desenvolvimento. Indicam-se as fontes históricas analisadas e a relação da EAAMT como expressão dos ideais de Brasil Moderno em Cuiabá. Como síntese final, esboçam-se os nexos entre os processos de modernização e de civilização orientados pelo Estado e pela elite nacional, e a educação para o trabalho destinado aos filhos da classe trabalhadora no âmbito do desenvolvimento do capitalismo no Brasil. 


\section{A modernização brasileira e a educação para o trabalho}

Ações voltadas à modernização brasileira e à educação para o trabalho foram amplamente discutidas e implementadas na primeira metade do século $\mathrm{XX}$. Essas açóes se traduziram em possibilidades de progresso, de industrialização, de urbanização do país, ainda que esses elementos esbarrassem na herança de um país conservador, escravagista, de economia rural, de uma população quase totalmente analfabeta.

Para Fernandes (1976), esse momento marca significativamente o desenvolvimento do capitalismo nos país, pois se inicia um processo que respondia à necessidade de alterar as práticas econômicas, políticas e sociais do passado.

Isso significa dizer que, na relação modernização-educação, havia reciprocidade entre o desenvolvimento econômico pretendido e a formação do povo brasileiro por meio da educação profissional. No período, a educação para o trabalho era considerada, pelas naçóes hegemônicas, expressão de um país civilizado e materialmente desenvolvido.

No Brasil republicano, esse entendimento aliava-se à ideia de que a educação profissional era uma alternativa para desenvolver hábitos de trabalho próprios do mercado moderno, úteis e necessários à naçáo, o que se consistiu no fundamento para que a Igreja, iniciativas particulares e o Estado propusessem ações educacionais.

Destacou-se, nesse campo, o projeto de formação cristã da ordem salesiana. Antes mesmo da criaçáo da primeira rede pública de educaçáo profissional, a rede de escolas de artes e ofícios, a Igreja católica já atuava na área educacional voltada ao trabalho. Ao final do século XIX, os salesianos já possuíam várias escolas no país e ministravam o ensino de ofícios como principal atividade, destinado aos jovens oriundos das camadas pobres, e ensino secundário e comercial, para as camadas médias.

No Rio de Janeiro, na época capital federal, particulares vinculados à Sociedade Propagadora das Belas-Artes chegaram a fundar, em 1858, uma escola, o Liceu de Artes e Ofícios do Rio de Janeiro, para formar artesãos e operários (MURASSE, 2001).

Ambas as atuaçóes, da Igreja e da iniciativa privada, remetiam a um processo de civilização que atendia aos apelos das elites intelectuais do Império para modernizar e civilizar o país, assim como proporcionava, mesmo que esparsamente, educação à sociedade, uma vez que náo era oferecida pelo 
Estado. Com o ingresso no século XX e a preocupação crescente da elite, agora republicana, com a massa de populares que se avolumavam nos centros urbanos, passou-se a exigir do setor público maiores esforços para atender às demandas sociais e educacionais que, afinal, estavam vinculadas ao desenvolvimento da economia.

A reorganização econômica dos países hegemônicos impunha novas diretrizes rumo à modernização capitalista. A educação pública, em especial a técnico-profissional voltada à classe trabalhadora, torna-se o eixo do progresso ansiado pela classe dirigente.

O primeiro [progresso técnico-científico] teve, na industrialização, o seu ponto nevrálgico; o segundo [o progresso moral], na educação pública, com especial atenção ao ensino técnico [...]. Modernizar e civilizar constituíram em dupla tarefa para a burguesia no aprimoramento, ou ainda, na retomada do desenvolvimento da ordem capitalista. (MURASSE, 2001, p. 8).

A organização da sociedade brasileira buscava se adequar a uma ordem social competitiva, em contraposição à dominação patrimonialista herdada da época colonial, que de forma gradual e combinada se tornou imbricada à lógica mundial (FERNANDES, 1976). A modernização dos métodos produtivos contou com a substituição do trabalho escravo pelo assalariado, o crescente uso da maquinaria e o investimento de capitais europeus no Brasil.

$\mathrm{O}$ grande contingente da população empobrecida, que se aglomerava nos centros urbanos, mereceu do Estado medidas repressoras que visavam ao controle social para a garantia da ordem pública com a perspectiva do "progresso ordeiro" ${ }^{3}$. Nesse sentido, ideologias burguesas concorreram para a consolidação de medidas e açóes capitaneadas pelas ideias maçônicas e orientadas pelo industrialismo ${ }^{4}$, que vinculavam o progresso à educação e ao desenvolvimento industrial.

3 Considerando os trabalhadores indispostos ao estudo, ao trabalho e, até mesmo, à higiene, a elite expressava hostilidade e os vinculava à desordem, pobreza e viciosidade. Postulava-se que o ensino obrigatório seria o elemento disciplinador e retificador que se esperava. Meninos "desvalidos, desgraçados, inocentes, infelizes, enjeitados" eram formas de tratar as crianças das classes populares (SCHUELER, 1999).

$4 \mathrm{O}$ industrialismo era a alternativa para o progresso da nação, que sairia de sua condição de nação atrasada para a de uma nação moderna, em face dos países ricos. A indústria estava vinculada ao progresso e à soberania econômica e política como símbolo da civilização (CUNHA, 2000). 
À transformação das práticas sociais, políticas e econômicas exigidas pelo processo de modernizaçáo, articulava-se o desenvolvimento de um capitalismo de caráter conservador e tradicionalista, em cujo processo o fazendeiro de café e o imigrante foram considerados importantes "táo somente nos limites em que suas atividades econômicas tiveram a significação de uma ruptura com o passado da era colonial" (FERNANDES, 1976, p. 91).

Variação típica do antigo "senhor rural", o fazendeiro de café procurava, a todo custo, manter seu status senhoril. O imigrante visava táo somente à riqueza pela riqueza e apenas tardiamente, ao poder e à dominaçáo a partir da acumulação da riqueza. No entanto, ambos demandavam esforços educativos do Estado. Como parte do operariado, os imigrantes necessitavam de educaçáo gratuita, enquanto que o fazendeiro, do qual emergiram as figuras do "coronel" e do "homem de negócios", exigia do Estado máo de obra qualificada que atendesse aos seus interesses.

O contexto apresentado permite indicar que a relação modernização-educação é o ponto de partida para encontrar elementos que se articularam no sentido da criação de uma rede de escolas destinadas a formar as novas gerações para o trabalho. Mesmo que o Estado republicano, no final do século XIX e início do XX, pouca ênfase tivesse dado à educação ${ }^{5}$, preocupando-se com os problemas mais imediatos, em especial o analfabetismo e a formaçáo nacionalista, a educação profissional adensou os interesses e os ideais que a elegeram como alternativa para solucionar as questóes sociais e econômicas do país.

\section{As Escolas de Aprendizes Artífices: um projeto nacional}

No governo do presidente Nilo Peçanha (junho de 1909 a novembro de 1910), elaborou-se um projeto nacional de escolas de formaçáo profissional, com foco no ensino de ofícios manuais que, sempre que possível, deveria adaptar-se à vocaçáo econômica local. Tão rapidamente, em 23 de setembro de 1909, o presidente Peçanha expede o Decreto no 7.566, criando dezenove

5 Para Saviani (2011), as primeiras décadas do século XX foram marcadas pelo esforço de organizaçáo das políticas educacionais que se fez sentir, mais fortemente, entre as décadas de 1920 e 1930, com as reformas de ensino ocorridas em vários estados (São Paulo, 1920; Bahia, 1925; Ceará, 1925; Minas Gerais, 1927; Pernambuco, 1928; e Distrito Federal, 1928), que objetivaram açóes, entre elas a adoção de novas práticas educativas. As reformas ofereceram as bases para o movimento escolanovista que ganhou evidência com a publicação do Manifesto dos Pioneiros da Educação Nova, em 1932 (GEBRIM, 2002). 
escolas, uma em cada estado federado, para ministrarem ensino profissional primário gratuito. $^{6}$

As dezenove unidades de EAAs foram instaladas, gradativamente, a partir do ano seguinte ao decreto de criação. A EAAMT, por exemplo, foi uma das primeiras escolas a entrar em funcionamento, fato que ocorreu em primeiro de janeiro de 1910, juntamente com as unidades de Goiás, Piauí e do Rio Grande do Norte. A EAA de Sergipe foi a última a ser instalada, quase dois anos mais tarde (primeiro de maio de 1911). Isso porque, embora criadas pelo mesmo decreto do presidente Peçanha, parte dos investimentos para instalação das EAAs cabia aos estados, como fornecer as instalações físicas (imóvel) para a União alojar suas escolas.

Os argumentos para justificar a criação das EAAs eram diversos. Kunze (2005), ao analisar a EAAMT, afirma que as autoridades republicadas do período desejavam ascender o país à modernidade com ações voltadas à educação profissional, aliadas aos ideais de governabilidade, democracia, descentralização política e industrialização.

De sua parte, Cunha (2000) analisa que o ensino de ofícios legitimava ideologias que tinham por base a motivação para o trabalho, antes menosprezado, pois se vinculava à atividade do escravo. Com a transição da Monarquia para a República, o trabalho passava a ser livre e assalariado, demandando mão de obra para os centros urbanos e para as indústrias em expansão.

Cunha (2000) discorre, também, acerca do fortalecimento do pacto federativo com a presença da União em todos os estados federados por meio das EAAs. De uma forma ou de outra, os gastos federais como a contratação de pessoal para ocuparem cargos nas escolas representaram reforços econômicos e possibilidades de alianças com lideranças políticas locais.

Nos documentos oficiais da época, pode-se observar que o governo republicano objetivava o assistencialismo destinado às massas populares. Naquele momento, adjetivados de ex-escravos, mendigos, negros, loucos, prostitutas, rebeldes, desempregados, órfã̃os e viciados, entre outros, os mais pobres "precisavam ser atendidos, educados e profissionalizados para se transformarem em obreiros, em operariado útil e incapaz de se rebelar contra a Pátria” (KUNZE, 2005, p. 32).

6 Essas escolas, inicialmente, ficaram vinculadas ao Ministério da Agricultura, Indústria e Comércio (MAIC), ao qual cabiam os assuntos relativos ao ensino profissional não superior. Mais tarde, em 1930, no início do governo de Getúlio Vargas, houve a transferência das EAAs para um novo ministério, o da Educação e Saúde Pública (MESP). 
Vê-se a utilizaçáo do adjetivo "desvalidos da fortuna" no argumento do presidente Peçanha para defender seu projeto de profissionalizaçáo da máo de obra industrial por meio das EAAs:

[...] o aumento constante da população das cidades exige que se facilite às classes proletárias os meios de vencer as dificuldades sempre crescentes da luta pela existência; que para isso se torna necessário, não só habilitar os filhos dos desfavorecidos da fortuna com o indispensável preparo técnico e intelectual, como faze-los adquirir hábitos de trabalho profícuo, que os afastara da ociosidade ignorante, escola do vicio e do crime. (BRASIL, 1909, p.1).

Considerando outras fontes, observa-se que essa proposta vinha ao encontro do interesse da elite, que manifestava medo das multidóes que começavam a se aglomerar nas principais cidades brasileiras, e uma educação que fosse preventiva, pensava-se, fazia-se necessária (CUNHA, 2000).

Em termos pedagógicos e ideológicos, as escolas de artes e ofícios não trouxeram novidades significativas. O que se viu de inovação foi a formação do primeiro sistema educacional de abrangência nacional, com propósitos comuns, cujo funcionamento se organizava por uma mesma legislação e vinculação a uma mesma esfera administrativa e pedagógica, no caso, o MAIC (CUNHA, 2000).

As escolas foram distribuídas de acordo com o caráter político-representativo do Senado da época e não segundo critérios econômicos. As fontes informam que cada um dos senadores da República barganhou uma escola para seu estado, com exceçáo do Rio Grande do Sul e do Distrito Federal, pois nessas localidades já havia instituiçóes com propósitos semelhantes, caso do Instituto Parobé, em Porto Alegre, e do Instituto Profissional Masculino, no Rio de Janeiro, instituiçóes posteriormente incorporadas à rede de EAAs (CUNHA, 2000). Com efeito, analisa-se que o dimensionamento do sistema e a localização das escolas, com algumas exceçóes, atendiam muito mais a interesses políticos do que aos arranjos produtivos locais.

Parte das análises do desenvolvimento da EAAs e também da EAAMT, que será tratada na seção seguinte, fundamentou-se em dezenove relatórios do MAIC de 1909 a 1930, e de um relatório do MESP de 1932. 
Essas fontes mostram que os maiores problemas das EAAs eram a precariedade das estruturas físicas das escolas e a dificuldade de contratação de profissionais para comporem o corpo docente. Os prédios cedidos pelos estados eram, em grande parte, locados e não adaptados, de forma que as aulas práticas, e também as teóricas (primário e de desenho), não podiam ser ministradas com a qualidade esperada.

A falta de profissionais para o corpo docente era tema frequente dos relatórios. Na época, não havia escolas de formação de professores para o ensino profissional, com exceção da Escola Normal de Artes e Ofícios Venceslau Braz, inicialmente fundada pelo município do Rio de Janeiro e posteriormente incorporada pela União. Contudo, uma única escola não atendia à demanda, o que tornava um desafio a constituição do corpo docente das EAAs e refletia na qualidade do ensino.

Essas dificuldades, entre outras, acarretavam a baixa frequência escolar dos discentes. Nos relatórios, ao final do relato de cada escola, segue uma tabela que contém a relação de disciplinas, cursos, número de alunos e a frequência escolar. Tudo indica que o Estado utilizava essas informaçôes para subsidiar decisôes e avaliar seu projeto de educação profissional.

Com base nessas informaçóes, considerando os problemas detectados, o governo republicano encomendou, na década de 1920, um plano de remodelação das unidades da rede que coube ao engenheiro e professor João Luderitz, da escola de Parobé, no Rio Grande do Sul, considerada detentora dos melhores resultados da rede. Luderitz desenvolveu seu plano entre os anos de 1920 e 1924, denominado Serviço de Remodelação. Como resultado, o MAIC publica uma portaria em 13 de novembro de 1926, sistematizando um novo regulamento para as EAAs, com base nos estudos da comissão de Luderitz.

Entre as novidades do novo regulamento, tinha-se a implantação da industrialização nas escolas, que foram autorizadas a receber e fabricar encomendas, o que já faziam, porém sem autorização. A venda de mercadorias dava à escola, aos seus alunos e professores a possibilidade de renda e atendimento ao mercado local. Essa portaria vigorou até que as escolas de artes e ofícios fossem incorporadas pelas escolas industriais ou escolas técnicas, fato que ocorreu em 1942, no governo Vargas, o qual visava atender de forma mais direta aos interesses dos industriais do Brasil. 


\section{A EAAMT: uma expressão dos processos de modernização em Cuiabá}

Neste estudo, a EAAMT foi compreendida no âmbito dos processos social, econômico e político do Estado, considerando-se a articulação entre a modernizaçáo e a demanda de civilização que orientou a elite republicana nas primeiras décadas do século passado. De área extensa no princípio do século XX, o estado de Mato Grosso ${ }^{7}$, desde sua ocupação pelos jesuítas no período colonial, tinha a atividade mineradora como maior expressão econômica. Essa atividade entrou em declínio após 1750, sendo seguida de novas atividades para a sustentação dos núcleos urbanos existentes, basicamente a criação de gado e a produção agrícola.

De 1864 a 1870, a Guerra do Paraguai tornou-se um marco do desenvolvimento econômico do estado, pela retomada da exploração de produtos extrativistas minerais, como diamantes, ouro e pedras preciosas, com o uso de melhores métodos e técnicas de extração, e maior investimento do exterior. Esse processo impulsionou a diversificação das atividades, de modo que, em 1900, "ilhas" de atividades econômicas configuravam o espaço mato-grossense (ABREU, 2014). ${ }^{8}$

O desenvolvimento econômico do estado ocorreu associado ao do país, contando com a construção de estradas férreas nacionais nas primeiras décadas do século XX, como a Madeira-Mamoré e a Estrada de Ferro Noroeste do Brasil, o incremento das comunicaçóes telegráficas, entre outros, em especial, da "Marcha para o Oeste" . O processo modernizatório materializou-se na transformação urbanística de Cuiabá que, em 1930, com Getúlio Vargas no poder, marcava o final da Primeira República.

Nessa conjuntura, a EAAMT foi parte constituída e constituinte, já que se articulava aos ideais de urbanização e progresso que impulsionavam

7 O estado de Mato Grosso abrangia uma parte de Rondônia e o atual estado do Mato Grosso do Sul, respectivamente desmembrados em 1943 e 1977.

8 Os grandes latifúndios de propriedade dos "coronéis" ou as áreas arrendadas por capitalistas com vinculação no mercado externo, que exploravam as potencialidades econômicas da região, constituíam as "ilhas" de atividades econômicas.

9 “'O resultado da 'Marcha para Oeste' incentivou o surgimento de novas cidades a partir das colônias agrícolas. A intensa propaganda do governo sobre estas colônias proporcionou um grande fluxo migratório de pessoas do Centro-Sul do país, principalmente de trabalhadores rurais" (AMEDI, 2012, p. 45). 
o desenvolvimento. Além disso, as fontes históricas acessadas ${ }^{\mathbf{1 0}}$ revelaram aspectos do funcionamento da EAAMT, que possibilitaram tecer os nexos constitutivos entre a educação para o trabalho ofertada em Cuiabá e o processo de modernização brasileira.

A Escola de Artes e Ofícios de Cuiabá foi instalada em um imóvel cedido pelo estado de Mato Grosso que, de forma semelhante ao das suas congêneres, não era próprio para um estabelecimento de ensino. Antes, o local abrigava a sede de uma chácara residencial nas proximidades do centro da cidade.

Sendo uma das primeiras do país a entrar em funcionamento, a EAAMT, de início, motivou esperanças das autoridades públicas locais, traduzindo-se em possibilidade de beneficiar os jovens das classes populares, podendo evitar a ociosidade e a criminalidade (MATO GROSSO, 1912).

No entanto, posteriormente, autoridades, como os governadores, passaram a expressar, em solenidades públicas, desencanto com a escola, emitindo declarações do tipo: "não possuímos o ensino profissional" e "é lamentável a falta, que se nota no Estado, de estabelecimentos [de educação profissional] de tão alta importância”.

Ao que tudo indica, a EAAMT não era considerada uma escola de educação profissional de qualidade, como mostram partes das mensagens enviadas pelos governadores Caetano Manuel de Faria e Albuquerque e Francisco de Aquino Correia, respectivamente, à Câmara de Deputados de Mato Grosso, na sessão de abertura do ano legislativo de 1916 e $1920:{ }^{11}$

A dizer a verdade, Snrs. Deputados, não possuímos o ensino profissional. É meu propósito não descural-o, visto como está reconhecido que nesse ramo do ensino publico repousa em grande parte a grandeza e prosperidade de um povo, como attestam a Inglaterra, Estados Unidos e Allemanha, sendo o recente espantoso progresso desta teve por fundamento o seu ensino thecnico profissional. S. Paulo ahi vai á frente como um exemplo do que vale o seu ensino que, se por um lado visa formar o professor,

10 O Estado acompanhava o desenvolvimento da EAAMT por meios de informações que lhe eram solicitadas. Essas informações eram compiladas em documentos como os relatórios pedidos pelo MAIC, já mencionados na seção anterior, e fontes produzidas pela própria EAAMT: as fichas de pagamentos extraordinários e os boletins de informações solicitados pelo MESP.

11 Optou-se por manter a grafia da época dos documentos citados. 
porque está convencido de que $<<$ a escola é o mestre $>>$, por outro lado se não esquece que na officina e no laboratório é onde se apparelham as forças com que devem contar as industrias diversas. (MATO GROSSO, 1916, p. 66, 67, grifo nosso).

Como se vê, é lamentavel a falta, que se nota no Estado, de estabelecimentos de tão alta importância. Não é de hoje que sábios pensadores consideram o ensino profissional como uma das bases mais seguras para reorganização da sociedade moderna. As naçóes mais poderosas dedicam-lhe especial attenção, certas de que sua grandeza e preponderancia dependem principalmente da capacidade de trabalho de seus filhos. (MATO GROSSO, 1920, p. 39, grifo nosso).

Essas citaçôes permitem também compreender a missão esperada da escola de Cuiabá, para a qual deveria empenhar-se: incitar o desenvolvimento industrial de Mato Grosso. Ou seja, acreditava-se que os investimentos em uma escola de formação para o trabalho pudessem produzir e reproduzir mão de obra que suprisse a demanda de trabalhadores de comportamento moderno e civilizado, e estimulasse a industrialização do estado.

Quanto aos processos pedagógicos, as fontes analisadas não dizem muito. O padrão de disciplina adotado, por exemplo, seguia o estabelecido pela Portaria MAIC de 13 de novembro de 1926 . Nesse regulamento, a manutenção da disciplina é colocada a cargo do diretor e, na falta deste, do escriturário. Cabia aos professores manter a disciplina na classe, fazendo observar os preceitos morais, que também faziam parte do currículo da escola.

Para além desse regulamento, não se obteve acesso à existência de alguma norma complementar. Considerando outras fontes, concluiu-se que as autoridades locais tencionavam que a escola adotasse padróes rígidos de disciplina, semelhante aos praticados pelas escolas militares, que no período imperial funcionou em Cuiabá ${ }^{12}$, como atesta a mensagem do governador Francisco de Aquino Correia:

12 Trata-se do Arsenal de Guerra da Província de Mato Grosso (1808-1915) e do Arsenal de Marinha da Província de Mato Grosso (1825-1878). Essas instituições, conduzidas pelo exército e marinha, instalados em Cuiabá, tinham muito mais características de asilos, orfanatos, abrigos, de natureza assistencialista e disciplinadora, do que locais próprios de ensino. 
Houve em Cuiabá, como sabeis, um Arsenal de Guerra, com uma companhia de menores aprendizes, militarmente disciplinados, que dalli sahiram transformados em centenas de artistas e cidadãos de merecimento. De ha muito que aquelle curso profissional foi extinto pelo Governo da Republica, substituindo hoje pela Escola de Aprendizes Artifices, que, entretanto, pela sua mesma organização, está longe de offerecer ao Estado idênticas nem semelhantes vantagens. Seria grande felicidade para o atual Governo, Srs., Deputados, poder realizar algum melhoramento em pról deste magno interesse do Estado. (MATO GROSSO, 1920, p. 39, grifo nosso).

Com base nos noticiários da imprensa local, Kunze (2005, p. 103) discute que a sociedade cuiabana também entendia que a EAAMT tivesse a possibilidade de recuperar, coibir e reprimir a "vagabundagem infantil". Talvez a razão disso resida na experiência de outros estabelecimentos antecessores à EAAMT, no caso, as escolas militares.

As mensagens dos governadores, como a seguir atesta parte da mensagem do governador Caetano Manuel de Faria e Albuquerque, expressam também que a escola de Cuiabá não preparava a "mocidade", não conseguia promover o seu desenvolvimento para produzir trabalho com inteligência, eficiência, utilidade para o emprego industrial. A mocidade, a que se referia o governador, era o público-alvo da EAAMT.

Não sendo ainda a Matto-Grosso permitido fornecer á sua mocidade um preparo para a vida real - a instrução thecnica profissional que completa a formação mental, dando-lhe maior efficiência, fazendo também o produtor, por crear no individuo a capacidade de trabalho intelligente, rendoso e util, tomaria a liberdade de vos lembrar a conveniencia de mandarmos para $S$. Paulo alguns jovens patricios e patricias, que desejam adquirir nos estabelecimentos profissionaes paulistanos alguma das varias profissóes, que são tão úteis na vida. (MATO GROSSO, 1916, p. 66, 67, grifos nossos).

Conforme os regulamentos do MAIC, esse público deveria ser formado pelos filhos das camadas mais pobres da sociedade cuiabana, os "desfavorecidos", entendendo-se, também, os "desafortunados", "ociosos”, "transgres- 
sores", "desvalidos da sorte". Esses adjetivos, utilizados para designarem os jovens filhos da classe trabalhadora, ajudam a desvelar, pelo menos em parte, o porquê do anseio do Estado e das elites locais para a adoção de padróes rígidos de disciplina, discutidos antes.

Além do critério socioeconômico estabelecido pela legislação federal jovem pobre -, os critérios físicos e biológicos eram exigidos para a admissão dos discentes. Esses requisitos especificavam que não deveriam ser aceitos jovens com vestígios de doenças infectocontagiosas e com defeitos físicos que os impossibilitassem de frequentar as oficinas de ofícios. Na escola cuiabana foram acrescidos outros critérios voltados ao gênero dos discentes (sexo masculino) e de saúde (vacinados).

$\mathrm{O}$ primeiro ano de funcionamento da EAAMT registrou oitenta e sete alunos matriculados, inicialmente abrigados nos cursos primários e de desenho, e que posteriormente seriam encaminhados a uma das cinco oficinas ofertadas: carpinteiro, alfaiate, sapateiro, seleiro e ferreiro (BRASIL, 1909-1910; 1912-1913). Essas oficinas, no geral, apresentavam condições estruturais inadequadas e consideradas impróprias para o desenvolvimento das atividades educativas, o que também se estendia aos demais espaços da EAAMT, como os problemas de higiene e falta d'água que refletiam negativamente na qualidade da educação (KUNZE, 2005).

Os cursos e currículos da EAAMT foram escolhidos e elaborados pelos professores e pela direçáo da escola, visto que as instruçóes iniciais davam autonomia pedagógica para propor o currículo escolar, desde que, em princípio, pudessem fornecer conhecimentos aplicáveis às atividades próprias do setor urbano e das indústrias locais (CUNHA, 2000). Esses cursos não inovaram em relação àqueles fornecidos por outras instituições, como as extintas escolas militares e o Liceu Salesiano de Cuiabá que, paralelamente à EAAMT, continuava em funcionamento.

Entendeu-se que a escola cuiabana considerou as experiências de educação profissional dessas escolas para alicerçar seu currículo, ou ainda que a escolha das oficinas tenha se limitado às condiçóes ofertadas na regiáo. Observou-se que os cursos ofertados não tinham relação direta com o contexto industrial de Mato Grosso, que era desigual e esparso, conforme já apresentado.

Importa observar que o ideal republicano em Cuiabá buscava conduzir os alunos a uma profissáo liberal, tida como modesta e autônoma, mas que se relacionava com a lógica do capitalismo moderno. Preconizava a garantia de 
aprendizagem de alguma técnica que fosse útil à sobrevivência nas cidades. Esse processo conduzia, também, os jovens aprendizes a se entenderem como responsáveis pelo seu sucesso ou ascensão social, diluindo-se a responsabilidade da sociedade pela sua situação de exclusão e confirmando a função de reproduzir e legitimar a desigualdade social, típicos do capitalismo.

Em relaçáo à autonomia pedagógica, assinala-se que essa perdurou até 1926, quando a Portaria MAIC de 13 de novembro foi expedida. Como referido na seçâo anterior, esse último regulamento, elaborado com base no Serviço de Remodelação, estabelecia a padronização pedagógica para todas as escolas que eram acompanhadas por meio dos documentos emitidos pela escola para composição dos relatórios do MAIC e os boletins de informaçôes solicitados pelo MESP.

As informaçóes dos dezenove relatórios expedidos pelo MAIC, entre os anos de 1909 e 1929, puderam ser agrupadas em quatro itens: da matrícula, da frequência e a da eliminação; a produção e a renda; a aquisição de materiais e obras; e a caixa de mutualidade e a merenda. Em praticamente todos os relatórios encontram-se informaçôes acerca do número de matrículas diurnas (total ou por curso) e da frequência média (geral ou por curso).

Com esses dados, as autoridades podiam ter em mãos uma espécie de censo escolar que subsidiava a distribuição de recursos ou a demanda de açóes de controle sobre o funcionamento da escola e, indiretamente, sobre os alunos.

Quanto aos boletins de informaçóes, observa-se que esses documentos solicitados ao MESP, em forma de fichas para preenchimento das escolas, foram produzidos entre os anos de 1931 e 1961. Para o estudo em questáo, foram verificados apenas os documentos produzidos pela EAAMT até o ano de 1942, recorte final adotado. Nessas fichas é evidente a preocupação das autoridades do Ministério por justificar o porquê da solicitação daqueles dados, apontando a importância da estatística para a civilidade moderna:

O pensamento moderno é notavelmente quantitativo, tanto em procedimento como em resultados. Já não podemos contar com as fórmulas de pensamento que serviam à humanidade desde Aristóteles até Huxley - baseadas em especulaçôes, categorias dialéticas e silogismos. Possuímos uma lógica diferente da dos nossos antepassados - uma lógica baseada nos números.

Dr. B. R. Buckingham, in. As estatísticas e o pensamento educativo moderno. (EAAMT, 1933, não paginado). 
Observa-se, ainda, nesses boletins, a ênfase dada às orientaçóes para o preenchimento correto do formulário. Essa ênfase traduz a importância dedicada às formas de registro do andamento das atividades das instituiçóes educacionais de todo o país, tratando as concepçóes adotadas uniformemente no âmbito da educação nacional.

Outras fontes foram pesquisadas, como as fichas de pagamento extraordinárias, nas quais se encontram registros de pagamento de remuneração aos discentes e funcionários da escola. Essas ficham eram distribuídas pelo MESP e confeccionadas em Campus, RJ, pela oficina de Artes Gráficas da escola fluminense. As fichas eram expedidas por mês de competência, com indicação da oficina e do trabalho realizado, e atestadas pelo diretor, escriturário e beneficiário (aluno ou professor).

As fichas especificam a porcentagem devida a cada beneficiado, distribuída como segue: $3 \%$ ao diretor, $3 \%$ ao secretário, $1 \%$ ao almoxarife, e $0,5 \%$ aos serventes. Quanto aos alunos, não se apresenta qual percentual era aplicado. Entretanto, na análise desses comprovantes há indícios de que uma quantia significativa cabia a eles, o que denota o atento à produtividade e ao trabalho "rendoso" como resultado do merecimento pelo esforço.

Com base nas fontes primárias pesquisadas, na revisão da literatura e outras fontes, constatou-se que a implantação da EAAMT se alinhava aos propósitos do Estado, também em vista dos mecanismos de organização e acompanhamento que orientavam seu funcionamento. Esse alinhamento abrangia o projeto de modernização e de civilidade em curso, como objetivo dos ideais republicanos.

\section{Considerações finais}

A EAAMT foi criada e implementada em um momento particular do processo de desenvolvimento do capitalismo no Brasil, ou seja, no início do século passado, quando estava em curso o ajustamento das relaçóes hegemônicas ao caráter conservador da sociedade brasileira, o que, segundo Fernandes (1976), traduziu-se em um desenvolvimento peculiar.

Esse movimento produziu tensóes e contradiçóes nas relaçóes econômicas, políticas e sociais entre os sujeitos envolvidos, quer seja o Estado, a Igreja, os representantes do capital, os intelectuais e a classe trabalhadora, que se manifestaram, entre outros, na educação profissional. 
O estudo permitiu concluir que a educação profissional estabelecida em Cuiabá por meio da Escola de Aprendizes Artífices de Mato Grosso constituiu um dos nexos do projeto maior de modernidade, que foi interpretado pelos estudiosos, em especial por Fernandes (1976), como a revolução burguesa no Brasil. Esse projeto, que tem desdobramentos na história da sociedade brasileira ainda nos dias de hoje, tinha como objetivo elevar a nação ao desenvolvimento e ao progresso, sedimentados pela industrialização e urbanizaçáo.

A partir dessas consideraçóes, pode-se afirmar a existência das relaçóes recíprocas e contraditórias entre a formação da educação profissional aos filhos dos trabalhadores, o que também era reivindicado por eles, e os interesses do Estado e das elites republicanas. Isso porque essa relação demonstrou-se necessária ao desenvolvimento do capitalismo no Brasil, o qual se constituiu materialmente combinando conservadorismo e tradição com modernização, progresso, civilidade, na perspectiva de uma educação profissional articulada aos processos de formação do trabalhador do mundo moderno.

\section{REFERÊNCIAS}

ABREU, S. Planejamento governamental: a Sudeco no espaço mato-grossense, contexto, propósitos e contradiçóes. Dourados, MS: Ed. Universidade Federal da Grande Dourados, 2014.

AMEDI, N. C. A cidade (res)significada: a ideologia de modernização de Cuiabá no período pós-divisão do estado de Mato Grosso. Revista Angelus Novus, São Paulo, n. 9, p. 41-64, dez. 2012.

BRASIL. Decreto no. 7.566, de 23 de setembro de 1909. Crêa nas capitaes dos Estados da Republica Escolas de Aprendizes Artifices, para o ensino profissional primario e gratuito. Diário Oficial, 26 set. 1909, p. 6.975, 1909. Disponível em: <http://www2.camara.leg.br/ legin/fed/decret/1900-1909/decreto-7566-23-setembro-1909-525411-publicacaooriginal-1-pe.html>. Acesso em: 1 mar. 2017.

. Ministério da Agricultura, Indústria e Comercio (MAIC). Ministerial Reports: Agricultura. 1910, 1911, 1912, 1913, 1914, 1915, 1916a, 1917, 1918, 1920, 1921, 1925 , 1926, 1928, 1929, 1929, 1930, 1933. Chicago, USA: Center for Research Libraries. Disponível em:<http://www-apps.crl.edu/>. Acesso em: 1 mar. 2017.

. Ministério da Educação e Saúde Pública (MESP). Ministerial Reports: Educação e Saúde Pública: 1933. Chicago, USA: Center for Research Libraries. Disponível em:<http:// www-apps.crl.edu/>. Acesso em: 1 mar. 2017.

CUNHA, L. A. O ensino nos primórdios da industrializaçáo. São Paulo: Ed. Unesp, 2000. 
EAAMT. Escola de Aprendizes Artífices de Mato Grosso. Boletins de informaçóes das EAAMT. 1933, 1934, 1935, 1936, 1937, 1938, 1939, 1940, 1941, 1942. Cuiabá, MT: Arquivo Histórico do Instituto Federal de Educação, Ciência e Tecnologia de Mato Grosso (IFMT), Campus Octayde Jorge.

. Folhas de pagamento das percentagens da administraçáo da EAAMT, ago.-set. de 1949; Folhas de pagamento por serviços extraordinários da EAAMT, ago.-out. 1940. Cuiabá, MT: Arquivo Histórico do Instituto Federal de Educação, Ciência e Tecnologia de Mato Grosso (IFMT), Campus Octayde Jorge, Cuiabá.

FAUSTO, B. História do Brasil. São Paulo: Edusp, 2015.

FERNANDES, F. A revoluçáo burguesa no Brasil: ensaio de interpretação sociológica. Rio de Janeiro: Zahar Editores, 1976.

GEBRIM, V. S. Psicologia e educação no Brasil: uma história contada pela Revista Brasileira de Estudos Pedagógicos. Goiânia: Ed. UFG, 2002.

HOLANDA, S. B. Raízes do Brasil. Rio de Janeiro: José Olympio, 1978.

IANNI, O. A ideia de Brasil Moderno. São Paulo: Brasiliense, 1996.

KUNZE, N. C. AEscola de Aprendizes Artífices de Mato Grosso (1909-1941). 2005. Dissertação (Mestrado em Educação)- Universidade Federal de Mato Grosso, Cuiabá, 2005.

MATO GROSSO. Presidential Messages (1830-1930): 1912, 1916, 1920, 1921, 1927, 1928 e 1929. Chicago, USA: Center for Research Libraries. Disponível em: <http://www-apps.crl.edu/>. Acesso em: 1 mar. 2017.

MURASSE, M. C. A educação para ordem e progresso do Brasil: o Liceu de Artes e Ofícios do Rio de Janeiro (1856-1888). In: SEMINÁRIO NACIONAL DE ESTUDOS E PESQUISAS "HISTÓRIA, SOCIEDADE E EDUCAÇÃO NO BRASIL": Transformaçôes do Capitalismo, do Mundo do Trabalho e da Educação, 5, 2001, Campinas, SP. Anais... Campinas, ago. 2001.

PRADO JÚNIOR, C. Formaçáo do Brasil contemporâneo. São Paulo: Companhia das Letras, 2011.

SAVIANI, D. A política educacional do Brasil. In: STEPHANOU, M.; BASTOS, M. H. (Org.). Histórias e memórias da educaçáo no Brasil. v. III: Século XX. Rio de Janeiro: Vozes, 2011. p. 29-38.

SCHUELER, A. F. M. Crianças e escolas na passagem do Império para a República. Revista Brasileira de História, São Paulo, v.19, n. 37, set. 1999. 